\title{
MEASURING SNOW MICROSTRUCTURE AND HARDNESS USING A HIGH RESOLUTION PENETROMETER
}

\author{
Martin Schneebeli", Christine Pielmeier \\ Swiss Federal Institute for Snow and Avalanche Research (SLF) \\ Jerome B. Johnson \\ U.S. Army Cold Regions Research and Engineering Laboratory-Alaska
}

\begin{abstract}
Using a high resolution snow penetrometer we are able to measure snow penetration resistance and snow meso- and microstructure. We can show that the variation of the signal is characteristic for different snow types. The penetrometer can be used in the field as well in the laboratory. The range of snow types which can be tested extends from light new snow $\left(50 \mathrm{~kg} \mathrm{~m}^{-3}\right)$ to very dense snow occuring on ski race tracks $\left(500 \mathrm{~kg} \mathrm{~m}^{-3}\right)$. The displacement resolution of the penetrometer is better than one millimeter to detect significant changes in resistance, the force signal is measured every $0.004 \mathrm{~mm}$. The penetration velocity is between $6-20 \mathrm{~mm} \mathrm{~s}^{-1}$.

A classification is developed to extract textural information of snow from the force signal. The classification is based on experiments with artifically metamorphosed snow and undisturbed snow from the Alps and Alaska. Two weak layers were identified and compared to surface sections.

The new instrument makes the measurement of mechanical and stratigraphic features of a snowpack a more objective and easy task than with other methods. The high displacement resolution promises also a better identification of weak layers.
\end{abstract}

KEYWORDS: snow hardness, metamorphism, snow strength, snow stratigraphy, texture

\section{INTRODUCTION}

The texture of snow (Arons and Colbeck, 1995) and its associated mechanical and physical parameters are of key importance to most scientific questions dealing with snow. Examples are mechanical properties of ski tracks, avalanche formation and availability of food to animals. However, a quantitative and rapid method for measuring the texture of snow is not currently available. At present, the methods to classify snow rely heavily on the experience of the user. In addition, the discrimination of layers is often very difficult and not without personal bias. Laboratory methods (surface or translucent sections, photography of single grains) give quantitative information. However, they are time consuming and the interpretation of the snow properties is often very difficult to do because stereological methods to characterize the mechanical properties of low density materials with complicated shapes are not well developed. Sieving gives at least a quantitative grain mass distribution, but loses all information about bonding properties. Schneebeli and Johnson (1998) developed a high resolution penetrometer to measure the stratigraphy and penetration resistance. This penetrometer has a high resolution in penetration resistance, but interpretation methods to obtain structural information were not developed. Schneebeli and Johnson (1998) reviewed also penetrometers previously developed and their shortcomings. In this paper we demonstrate that our high resolution penetrometer, with a higher measurement frequency, can delineate different snow texture types. This should enable us to measure snow texture and its mechanical properties much more objectively and rapidly.

\section{CONSTRUCTION}

The penetrometer (called SnowMicroPen) consists of a small flared measuring tip, $5 \mathrm{~mm}$ diameter with a $60^{\circ}$ degree included angle (Fig. 1). This tip is connected to a high resolution force trans-

- Corresponding author address: Martin Schneebeli, Swiss Federal Institute for Snow and Avalanche Research (SLF), CH-7260 Davos Dorf, Switzerland; tel: +4181417 111; fax: +41 81417 110; email: schneebeli@slf.ch 
ducer which is housed in a drive cone and rod of $16 \mathrm{~mm}$ diameter. The drive rod is geared and driven by a constant speed rotary motor (Johnson and Schneebeli, 1997). The force transducer has a range from $0-500 \mathrm{~N}$ and a resolution of $0.01 \mathrm{~N}$. The penetration velocity is 20 $\mathrm{mm} \mathrm{s}^{-1}$, but can be varied between about 5-30 $\mathrm{mm} \mathrm{s}^{-1}$. A force measurement is acquired every 4 $\mu \mathrm{m}$, independent of penetration velocity. At the most often used velocity of $20 \mathrm{~mm} \mathrm{~s}^{-1}$ the sampling frequency is $5000 \mathrm{~Hz}$.

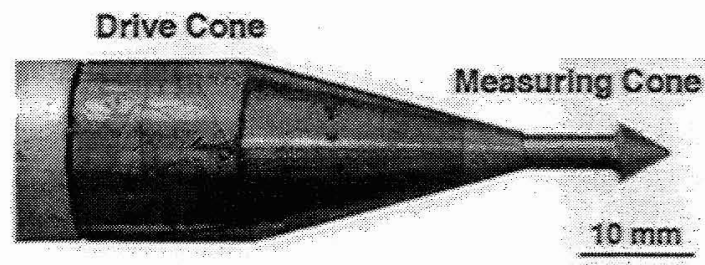

Figure 1. Construction of the tip section of the penetrometer

The electronics are housed in a small box. Data tranfer is via the parallel interface to a notebook computer. The data acquisition software runs on the MS-DOS operating system. The motor and the drive cone (length $1.7 \mathrm{~m}$ ) are mounted on two rods with an included $60^{\circ}$ angle (Fig. 2). The total weight of probe and electronic box is $8.5 \mathrm{~kg}$. Measurements are always taken perpendicular to the slope. This is different from the usual measurement practice using the classical rammsonde. Measurements perpendicular to the slope show less error at the interface going from a weak layer to a hard or crusty layer. The reaction force is exerted by leaning on the motor housing. Experience shows that snow layers with a hardness up to knife can be easily measured. Even harder snows can be measured using a fixed frame (laboratory version) or a specially designed sledge, which can be fixed with snow screws.

One high resolution force recording of $1.5 \mathrm{~m}$ depth has $375^{\prime} 000$ readings. Depending on the format of storage, this results in a file size between $750 \mathrm{~K}$ Byte to about $2.5 \mathrm{M}$ Byte. To minimize the size of the files the numbers are stored in binary format. A custom program, which can be easily interfaced with the Info-Box program (Russi et al., 1998) visualizes the data files and can export the files in ASCII format, which can be read directly by spreadsheet programs.

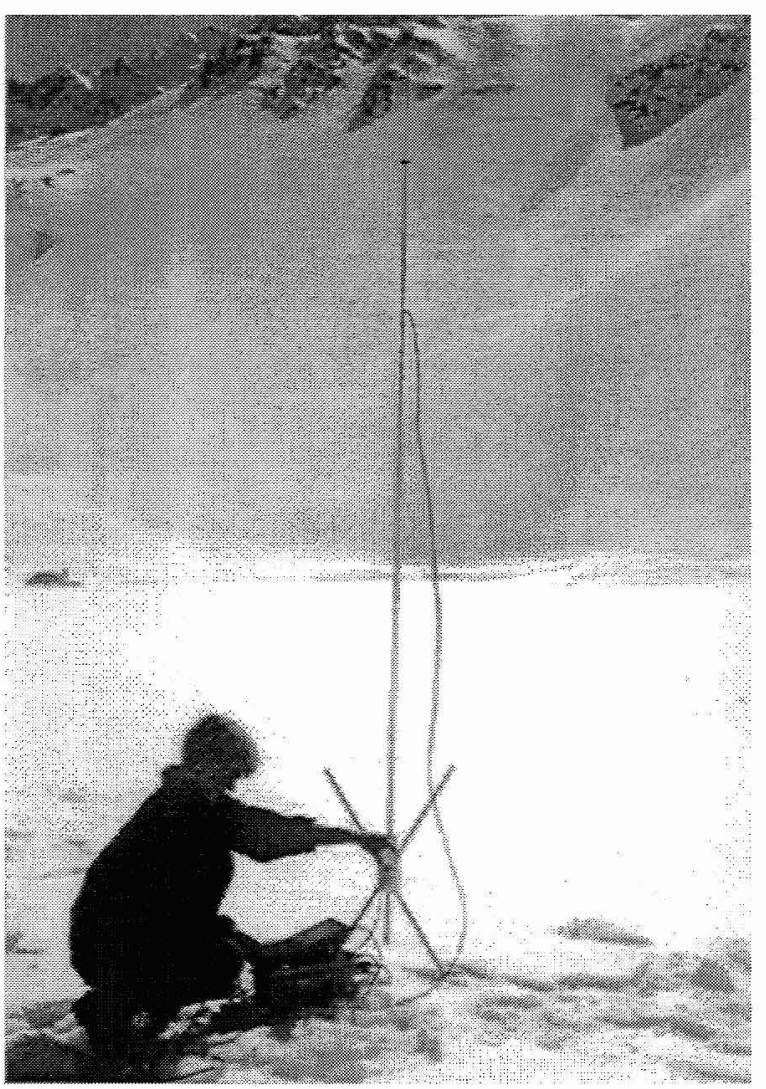

Figure 2. Field version of the SnowMicroPen. Visible are the motor housing (below the hand of the operator, the drive cone, the mounting rods, the electronics box and the computer (Photo: A. Roth, SLF).

\section{DEFINITION OF A TEXTURAL INDEX}

It is well known that the mechanical properties of snow are not only dependent on density, but also much influenced by its texture. Texture is often described in terms of grain shape. During the evaluation of the penetration measurements we found that grain shape is not ideally suited to parameterize the structural changes occuring in snow. We found that the ratio of mean grain size $[\mu \mathrm{m}]$, determined by sieving and calculated after Friedman and Sanders (1983) divided by the density of snow $\left[\mathrm{kg} \mathrm{m}^{-3}\right]$ gives us a good measure. The calculation of the texture index is based on the idea that smaller structural elements have a decreasing ratio between mean grain size and volumetric density (see fig. 3 ). The 
texture index is also a direct index of the volume density of bonds.

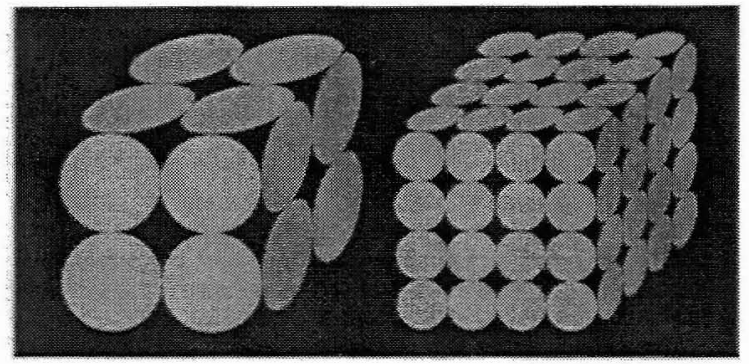

Fig 3 A cube consisting of large grains has fewer contact points than a cube of the same dimension consisting of small grains. Both cubes have the same volumetric density. The texture index (TI) of the left configuration is 3.8 , while the cube on the right has a $\mathrm{Tl}$ of 1.9 .

This concept can be well adapted to snow and could be an effective tool to quantitatively measure complex interactions between grain shape and density (e.g. bond sites).

\section{CORRELATION OF THE TEXTURAL INDEX TO MEASUREMENTS}

To correlate the texture index to the force signal of the SnowMicroPen we measured 23 different snow samples. These snow samples cover all 5 major snow classes. The texture index $\pi$ was determined by measuring density and mean grain size by sieving. The penetration force measurements were split in sections of 1000 data points, corresponding to $4 \mathrm{~mm}$ of penetreted snow and the coefficient of variation (c.v.) (standard deviation divided by the mean) was calculated on each segment. A linear regression model resulted in the following coefficients:

$\mathrm{TI}=1.45+5.72 \mathrm{c} . \mathrm{V}$

The coefficients are highly significant $(p<0.001)$ and the coefficient of correlation $r$ is 0.89 . Based on this result, the texture index can be calculated easily from penetration measurements.

\section{CASE STUDIES}

The SnowMicroPen has been tested on a wide range of snows, from light new snow $\left(50 \mathrm{~kg} \mathrm{~m}^{-3}\right)$ to very dense snow occuring on ski race tracks $\left(500 \mathrm{~kg} \mathrm{~m}^{-3}\right)$. We will describe in this section several case studies. The texture resolving capabilitiy is demonstrated first on two snows from Fairbanks, Alaska. The snow shown in Fig. 4 was deposited on a wooden table in an open area. Only small and reversing temperature gradients developed due to the access of air to the underside of the table. The density of the snow is 229 $\mathrm{kg} \mathrm{m}^{-3}$, and the mean grain size, determined by sieving, is $1.9 \mathrm{~mm}$.

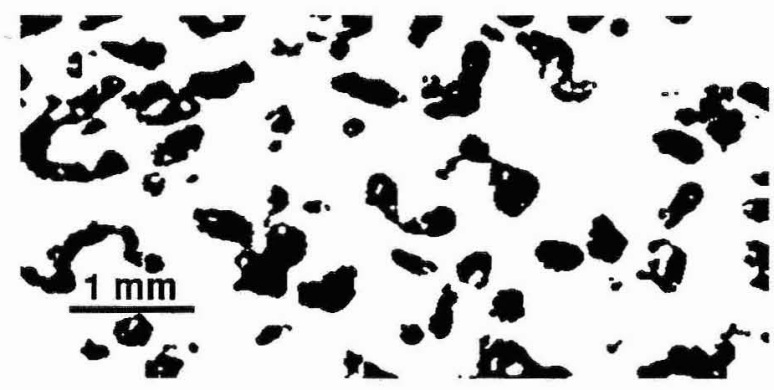

Fig. 4a Surface section of about 3 month old Alaskan equitemperature metamorphosed snow. On this and the following surface section ice is represented by black, air by white.

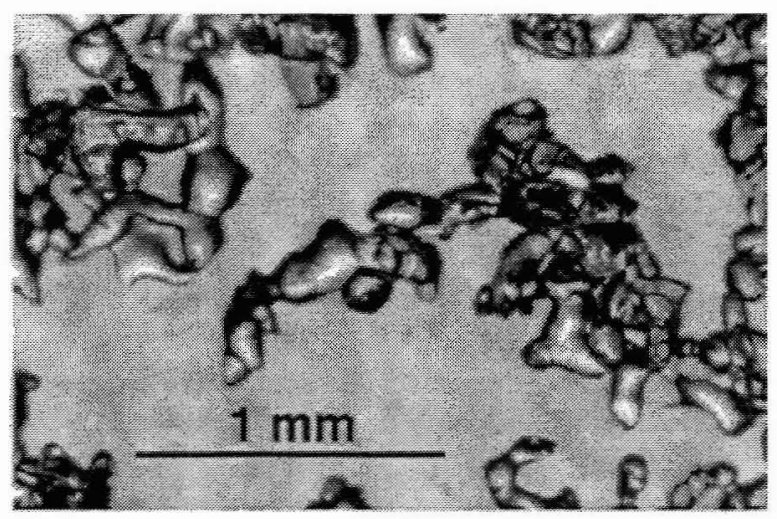

Fig. 4b Grain photography (Photo: M. Sturm) of 3 month old equitemperature metamorphosed snow.

A small part of the penetration measurement (4 $\mathrm{mm}$ of a total of $120 \mathrm{~mm}$ of the sample) is shown in fig. 4. The signal varies rapidly between peaks and valleys. A lower frequency component can be observed with a range of about $0.2 \mathrm{~mm}$, as well as a higher frequency component with a range of about $0.01 \mathrm{~mm}$. The higher frequency 
range is at the detection limit of the displacement resolution of the penetrometer.

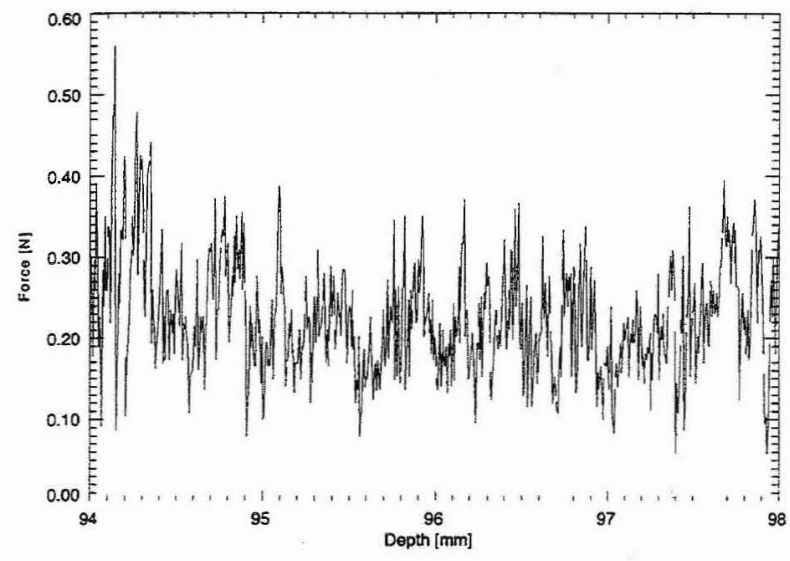

Fig. 5 Penetration measurement made in equitemperature metamorphosed fine grained snow shown in Fig. 4

The snow shown in fig. 6 is from the same location as the equitemperature metamorphosed snow, but from the ground. Large temperature gradients across the snow produced a mature depth hoar.

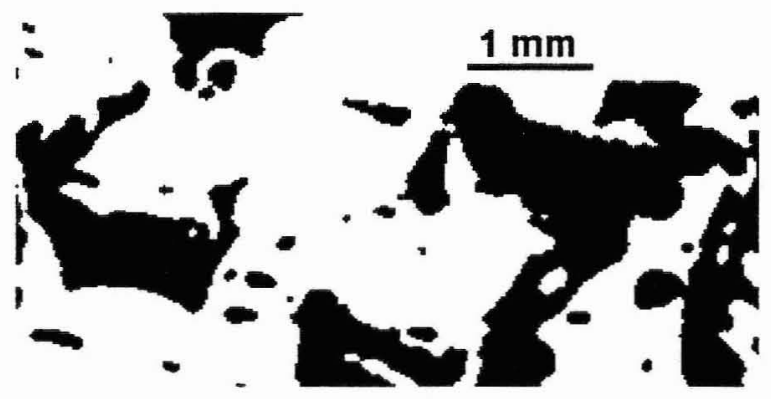

Fig. $6 a$ Surface section of Alaskan depth hoar snow.

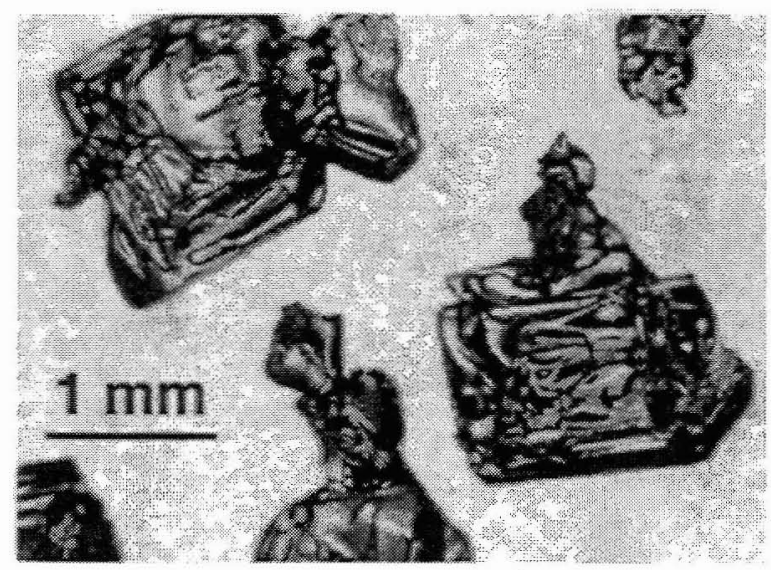

Fig. 6b Grain photography (Photo: M. Sturm) of Alaskan depth hoar snow
The density is $238 \mathrm{~kg} \mathrm{~m}^{-3}$, only slightly higher than the density of the equitemperature metamorphosed snow. The mean grain size is $1.9 \mathrm{~mm}$. The penetration measurement (fig. 7) is very different from fig. 4 . It shows a distinct zigzag pattern, consisting of a rising slope in the direction of the penetrometer movement, and a very rapid fall. This pattern shows a typical separation distance of $0.2-0.4 \mathrm{~mm}$. The mean penetration force is $0.16 \mathrm{~N}$ in the case of the equitemperature (ET) snow, and half of that, $0.08 \mathrm{~N}$ in the case of the depth hoar. The peak resistance is $0.54 \mathrm{~N}$ for the ET snow, and $0.78 \mathrm{~N}$ for the depth hoar (statistics from complete sample, penetration length $120 \mathrm{~mm}$ ). This result can be interpreted either with a micromechanical model (Johnson, 1998, this issue) or by a statistical approach, as will be used here.

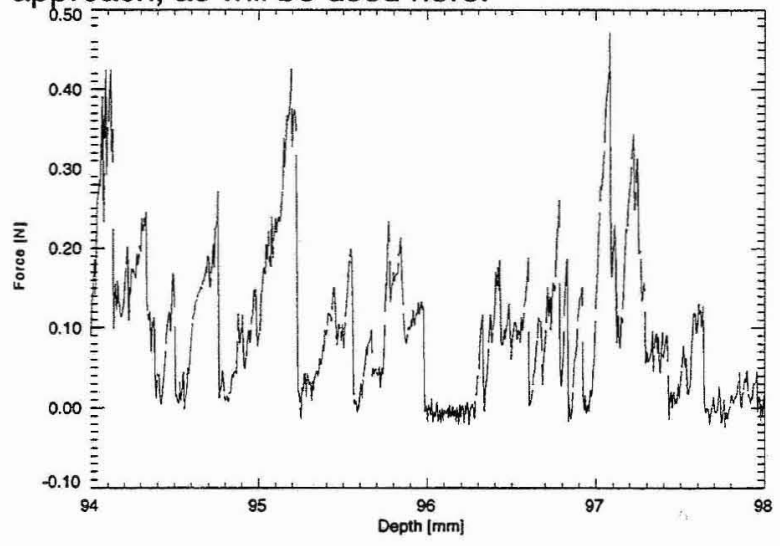

Fig. 7 Penetration measurement made in depth hoar shown in Fig. 6

Our interpretation of the natural snow penetrometer measurements were confirmed using controlled temperature gradient (TG) experiments. New snow was sieved into a well insulated box with a heating plate at the bottom. The bottom was kept at $-2^{\circ} \mathrm{C}$, while the top was at $-10^{\circ} \mathrm{C}$. 20 $\mathrm{cm}$ of snow were in the box, resulting in a temperature gradient of $40^{\circ} \mathrm{C} \mathrm{m}^{-1}$. The changes in snow density and mean grain size are shown in table 1.

\begin{tabular}{llllll}
\hline sample & M11 & M12 & M13 & M14 & M15 \\
\hline day & 0 & 7 & 14 & 23 & 30 \\
mean grain size $[\mathrm{mm}]$ & 0.46 & 0.52 & 0.76 & 1.1 & 1.15 \\
density $\left[\mathrm{kg} \mathrm{m}^{-3}\right]$ & 178 & 225 & 227 & 245 & 224 \\
\hline
\end{tabular}

Table 1 Parameters of the snow metamorphosed under controlled conditions: day of sampling after temperature gradient applied, density of snow and mean grain size, determined by sieving. 


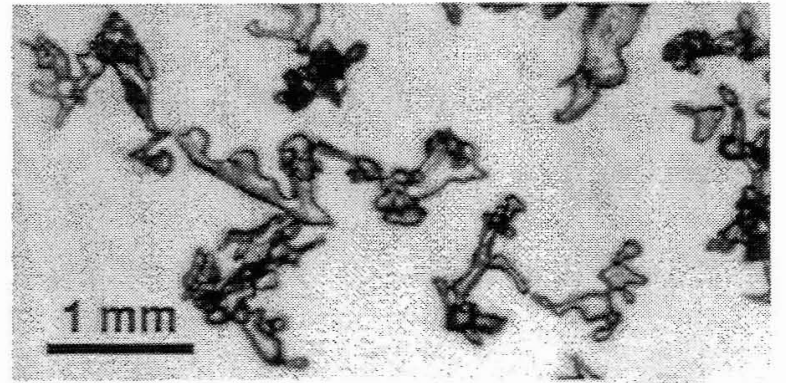

Fig. 8a TG experiment at start (M11).

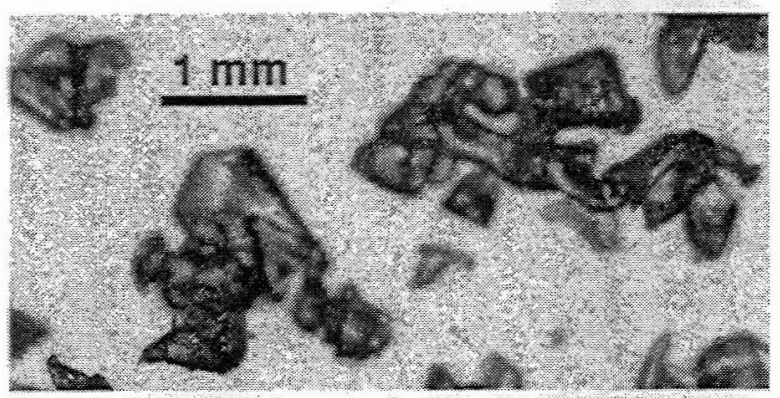

Fig. 8b TG experiment after one week (M12).

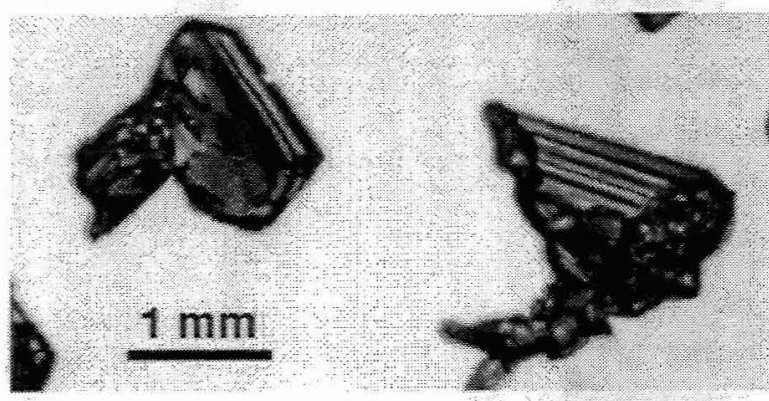

Fig. 80 TG experiment after two weeks (M13).

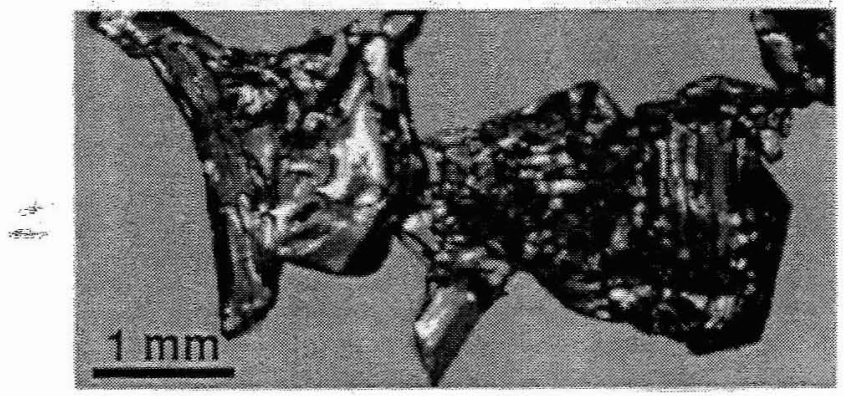

Fig. 8b TG experiment after three weeks (M14).

The penetration resistance of these different snow types is shown in fig. 9. The median force and its variability decrease until week 2 . At this time most of the grains are faceted, and the coefficient of variation (standard deviation/mean) is steadily increasing. The snow shows its minimal resistance, and we interpret this as the moment when most original bonds are dissolved. After that an increase in the median penetration force can be observed, together with a very strong increase in penetration variability.

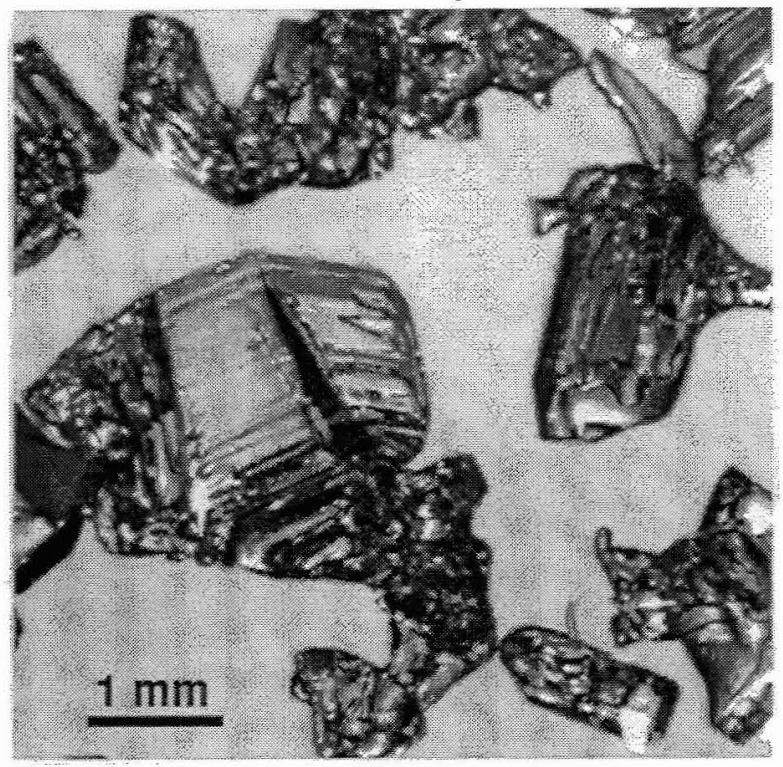

Fig. 8b TG experiment after four weeks (M15).

We observed that at this time chains of grains (up to 4 and more crystals) have been developed. No compressive tests could be conducted after week 2 (M13), due to the increasing fragility of the snow. We conclude that during the formation of depth hoar two different processes occur: first a dissolution of bonds followed by a formation of bonds in direction of the temperature gradient. The subsequent increase in penetration resistance is followed by increased structural instability.

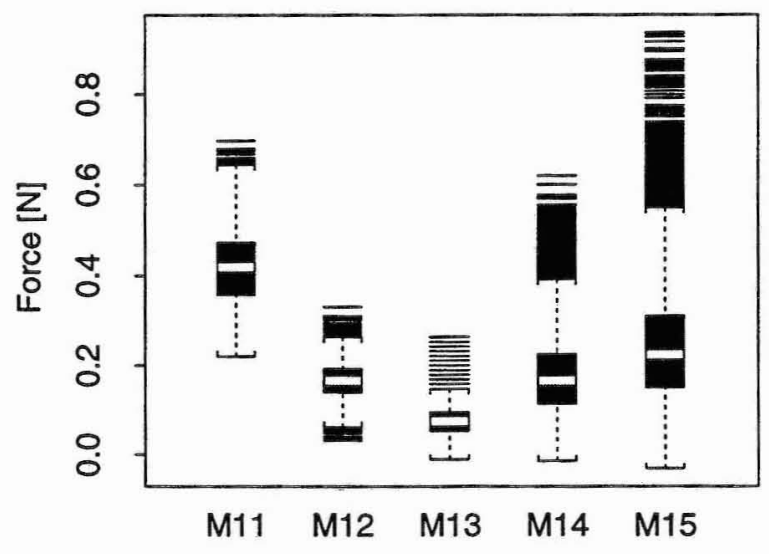

Fig. 9 Box plots of penetration resistance measurements in the TG-controlled laboratory experiment. The individual boxes show: the median as horizontal line at the interior of the box, the box itself represents the interquartile distance (IQD) (50\% of data), the whisk- 
ers extend to $1.5 \times$ IQD from the center. Extreme values are shown by individual horizontal lines (most obvious at M15).

\begin{tabular}{|c|c|c|c|c|c|}
\hline sample & M11 & M12 & M13 & M14 & M15 \\
\hline day & 0 & 7 & 14 & 23 & 30 \\
\hline$T I_{m}\left[10^{-3} \mathrm{~m}^{4} \mathrm{~kg}^{-1}\right]$ & 2.6 & 23 & 3.4 & 4.5 & 5.2 \\
\hline coeff. variation [] & 0.1 & 0.22 & 0.4 & 0.43 & 0.47 \\
\hline $\mathrm{TI}_{\mathrm{c}}\left[10^{-3} \mathrm{~m}^{4} \mathrm{~kg}^{-1}\right]$ & 2.0 & 27 & 3.7 & 3.9 & 4.1 \\
\hline
\end{tabular}

Table 2 Texture index $\mathrm{TI}_{\mathrm{m}}$ (calculated from mean grain size and density), the coeffient of variation from the penetrometer resistance and texture index $\mathrm{TI}_{\mathrm{c}}$ calculated based on the regression.

To investigate the possibility to detect critical layers for slab avalanche formation penetration resistance was measured on two typical layer interfaces. The first interface was a small slab consisting of wind transported new snow atop a melt-freeze layer. The interface between the melt-freeze layer and the slab shows large holes bridging the separations between the melted grains (fig. 10). These holes act as a "weak layer".

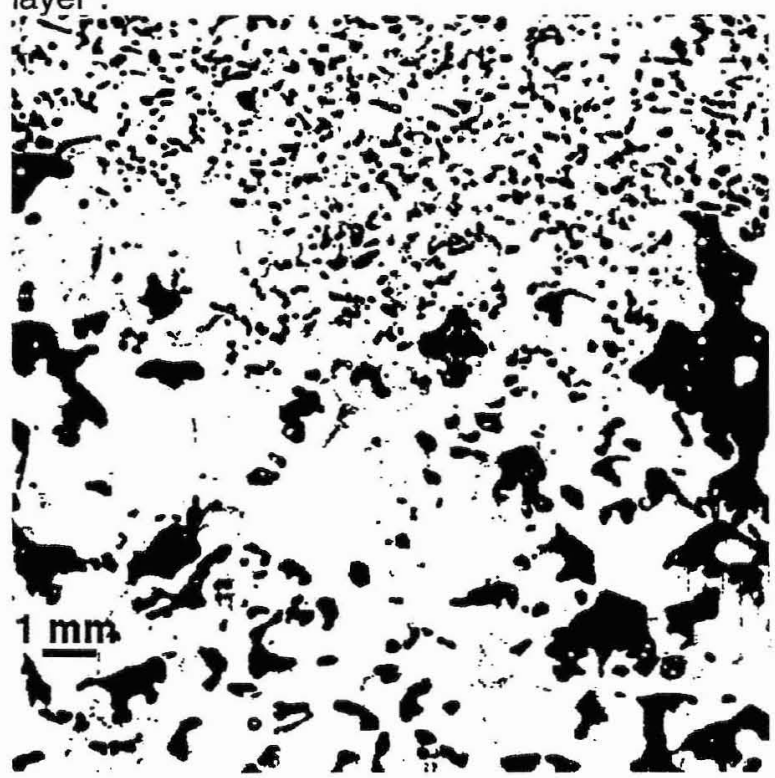

Fig. 10 Surface section of interface between meltfreeze crust and fine grained wind transported snow. Remark the large pores at the interface between coarse and fine snow.

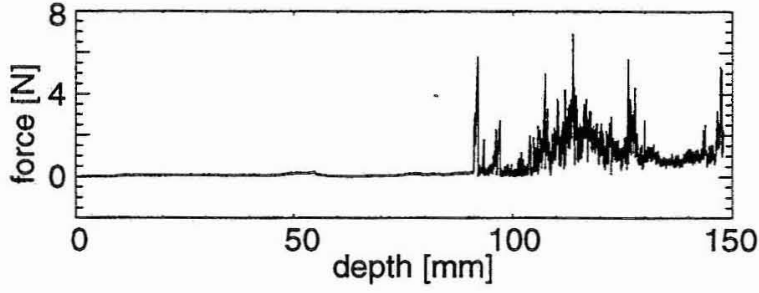

Fig. 11 Penetrometer measurement of the slab example. Fracture occurred at $95 \mathrm{~mm}$.

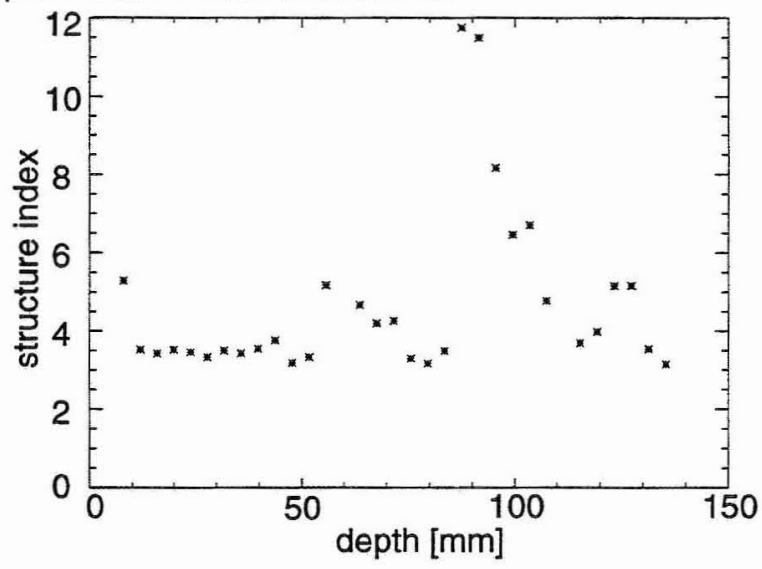

Fig 12 Texture index of slab example. The texture index shows the highest value at the location of the fracture.

A more classical weak layer was found at the test site of SLF at Weissfluhjoch. The profile at the relevant position has been described by $T$. Stucki (pers. comm.), see table 3.

\begin{tabular}{llll}
\hline $\begin{array}{l}\text { height [cm] } \\
\text { (depth [mm]) }\end{array}$ & snow type & diameter & hardness \\
\hline 174 & $2(3)$ & $0.25-1.5$ & 2 \\
171 & 23 & $0.25-0.75$ & $1-2$ \\
169 & $2(3)$ & $0.25-1$ & 2 \\
167 & $2(3)$ & $0.25-1$ & $1-2$ \\
$166(327)$ & $3(2)$ & $0.25-0.5$ & 3 \\
$162(340)$ & 47 & $0.5-1.5$ & 1 \\
$161(348)$ & $9 e$ & 0.5 & 4 \\
$160(359)$ & 23 & $0.25-1.5$ & $2-3$ \\
$157(392)$ & $3(2)$ & $0.25-0.5$ & 4
\end{tabular}

Table 3 Relevant portion of profile at test site Weissfluhjoch on 15 April 1998. The weak layer is marked in grey. Designation of snow type follows international classification. 
The weak layer is described as partly consisting of depth hoar and faceted crystals. The position of the layers corresponds within the precision of field profiles. The corresponding penetrometer measurement is shown in fig. 13. It clearly shows a dip of very low resistance at the location of the observed weak layer. It can also distinguish very clearly between the following hard crust.

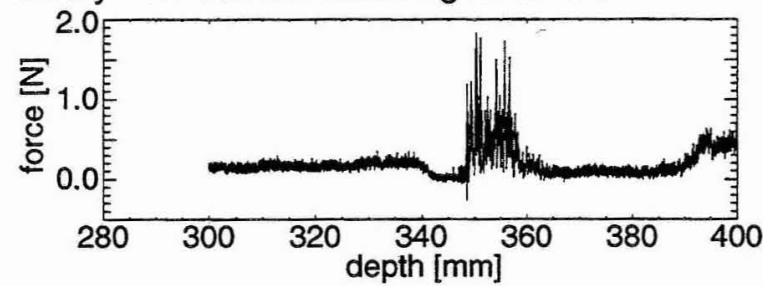

Fig 13 Penetration measurement at the test site with weak layer between $340-348 \mathrm{~mm}$ above a melt-freeze crust.

The texture index $\mathrm{Tl}$ again shows the position of the critical layer. However, $\mathrm{TI}$ is misleading in this case. Because $\pi$ has to be calculated over a lenght of $4 \mathrm{~mm}$, the high value at $348 \mathrm{~mm}$ is caused by the very rapid change of the penetration resistance. $T$ can only be confidently applied in snows which are homogenous over the length of calculation.

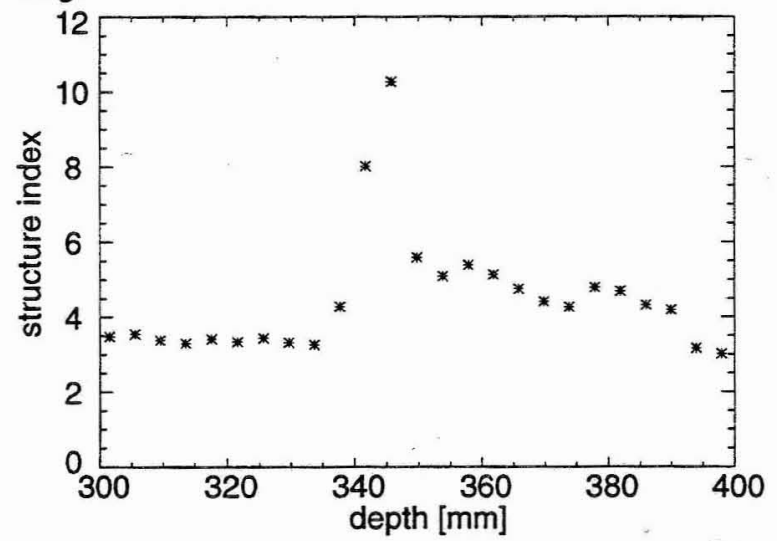

Fig 14 Texture index of of the penetration measurement at the test site. The maxima is located at the position of the weak layer.

\section{CONCLUSIONS}

The SnowMicroPen is able to measure structural and spatially highly resolved mechanical parameters with a simple penetration measurement. Laboratory tests on snow metamorphosed under controlled conditions show a mechanical behavior which has not been described until now be- cause of the lack of an instrument capable of measuring such delicate materials. The SnowMicroPen makes a quantitative measure of penetration resistance and texture, a task which in this precision would take hours instead of minutes with other methods. Even more exciting will be the link to micromechanical models. We may then be able to give an even better explanation of the mechanical behavior of a snow pack.

\section{ACKNOWLEDGEMENTS}

We thank W. Caviezel and R. Wetter, for constructing the apparatus, $M$. Roveretto and $M$. Steiniger, for writing the PeneWin program, $\mathrm{P}$. Berther, for evaluting many technical details , R.L. Brown and P. Satyawali for sharing the work in the cold rooms, J. Schweizer for reviewing.

\section{REFERENCES}

Arons, E.M., Colbeck, S.C., 1995: Geometry of heat and mass transfer in dry snow: a review of theory and experiment. Rev. Geophys. 33, 463-493.

Friedman, G.M., Sanders, J.E., 1983: Principles of sedimentology. Wiley, New York.

Johnson, J.B., 1998: Characterizing the microstructural and micromechanical properties of snow (this issue)

Johnson J.B., Schneebeli M.,1997: US Patent Application 08/850,160.

Russi, T., and others, 1998: The Swiss avalanche 2000 programm (this issue)

Schneebeli M and Johnson J.B., 1998: Ann. Glaciol., 26, 107-111. 